\title{
Certification of sodium benzoate solution reference material by HPLC-UV, LC-MS/MS and UV-VIS-NIR spectrophotometry for food and drug analysis
}

\author{
Adel B. Shehata $\oplus^{*}$, Abdulrahman R. Alaskar $\odot$,
}

Mohammed A. Alrasheed $\odot$, Abdullah S. Alosaimi $\odot$,

Fahd A. Alkharraa $\odot$ and Abdulrahman M. Alzahrani

\author{
Saudi Standards, Metrology and Quality Org./National Measurement and Calibration Center \\ (SASO/NMCC), P. O. Box 3437 Riyadh 11471 KSA
}

(Received August 23, 2020; Revised October 10, 2020; Accepted October 14, 2020)

\begin{abstract}
Sodium benzoate is one of the most widely used food perseverates and has to be used in regulated amounts to avoid its harmful health effects. Reviewing the scientific literature for traceability of the analytical measurement results of sodium benzoate in various food and drug applications to the SI units, it has been found that no scientific details of certification of sodium benzoate CRMs used for the calibration of measuring equipment are published. For this reason, the national metrology institute of Saudi Arabia (SASO/NMCC) certifies a sodium benzoate solution reference material. In this work, sodium benzoate was synthesized, purified and a batch solution reference material was prepared as $1014.47 \mathrm{mg} / \mathrm{kg}$ then homogenized and bottled. Homogeneity and stability of the candidate RM were assessed and the results obtained showed that the material is sufficiently homogeneous and stable. Characterization of the reference material was carried out by HPLC-UV, LC-MS/MS and UV-VIS-NIR spectrophotometer as three independent methods. The certified value was derived by combining data from the three methods using the weighted mean approach and was found $1016.13 \mathrm{mg} / \mathrm{kg}$. The certified uncertainty was calculated as weighted uncertainty and was found $10.47 \mathrm{mg} / \mathrm{kg}(1.03 \%)$. Sources of this uncertainty were identified from the characterization, $u_{c h a r}$, homogeneity, $u_{h o m}$, and long-term stability, $u_{l t s}$, as well as the bias allowance, $B$.
\end{abstract}

Keywords: RM preparation; sodium benzoate; homogeneity; stability; characterization; certified value. (C) 2020 ACG Publications. All rights reserved.

\section{Introduction}

The concept of establishing traceability of the chemical measurement results to the SI units is of fundamental importance for the credibility and comparability of measurement results [1]. Chemical measurements are performed widely in food and drug industry for the purpose of ensuring food quality and safety where certified reference materials (CRMs) are used as a tool for linking the measurement results to the SI units [2,3]. Certified reference material is defined as: reference material, accompanied by documentation issued by an authoritative body and providing one or more specified property values with

\footnotetext{
*Corresponding author: E-Mail: adelshehata63@yahoo.com ; a.shehata@ saso.gov.sa
} 
associated uncertainties and traceabilities, using valid procedures [4]. CRMs are generally prepared in batches for which the property values are determined within the stated uncertainty limits by measurements on sample representative for the whole batch. They are used for calibration of an apparatus, method validation, assessment of method and instrument performance, establishing traceability of the measurement results, and determining the uncertainty of these results [5,6].

In this context, sodium benzoate is widely used as food preservative in processed foods such as ketchup, sauce, soda, juice and so many others and it has been reported that the maximum limit of it allowed by the FDA is $0.1 \%$ and $200 \mathrm{mg} / \mathrm{L}$ by the European Regulation 92/2/EC [7]. If the uptake of sodium benzoate is higher than the above mentioned permitted limits, it can be harmful where it causes allergic effects, such as urticaria, non-immunological contact urticaria and asthma [7]. Therefore, analytical methods used for determination of sodium benzoate should be of sound creditability since food analysis is of an utmost importance for food producers, consumers and regulators [8]. Reviewing the literature for the traceability of the wide volume of sodium benzoate measurement results to the SI units, it was found that no published research illustrating the scientific and metrological details of certification of solution sodium benzoate reference material is available. Therefore, the aim of the national metrology institute (NMCC/SASO) of Saudi Arabia behind this research was to cover this gap.

A batch solution reference material was prepared by dissolving a known mass of pure sodium benzoate in $11 \mathrm{~L}$ ultrapure water and its concentration was calculated as $1014.473 \mathrm{mg} / \mathrm{kg}$. The RM batch was homogenized and bottled in $100 \mathrm{HDPE}$ bottles each is $100 \mathrm{~mL}$. Homogeneity, stability, characterization and value assignment for the reference material were carried out in accordance with the requirements of ISO 17034 and ISO Guides 35 [9, 10]. Characterization of the candidate RM was performed using HPLC-UV, UV-VIS-NIR spectrophotometer, and LC-MS/MS as three independent methods. The concentration of the RM was found $1015.06,1016.72$ and $1019.52 \mathrm{mg} / \mathrm{kg}$ by the three methods respectively, which indicates a very good agreement between them and the gravimetrically prepared one. The certified value and the certified uncertainty were assigned as weighted mean and uncertainty by combining the data obtained from the three methods based on the Paul and Mandel statistical model $[11,16]$. Details of this work are described in this article.

\section{Materials and methods}

\subsection{Reagents and Solvents}

Benzoic acid (99.5\%) and sodium hydroxide (98-100.5\%) were purchased from Panreace, Germany. Ammonium acetate $(98.5 \%)$ was obtained from VWR, Belgium and sodium salicylate (99101\%) was obtained from Acros, Belgium. Acetonitrile, methanol (HPLC Grade) and Glacial acetic acid were purchased from Fisher, UK, Canada and USA respectively. Ultrapure water was obtained from Millipore Milli-Q RG, USA. The sodium benzoate CRM was synthesized and purified by SASO/NMCC, KSA then certified for purity by qNMR at the National Metrology Institute of Turkey, UME as $99.997 \pm$ 0.232 .

\subsection{Synthesis of Sodium Benzoate}

Pure sodium hydroxide $(8 \mathrm{~g})$ was dissolved in $100 \mathrm{~mL}$ ultrapure water to prepare $2 \mathrm{M}$ solution, which was added to $24.4 \mathrm{~g}$ of solid pure benzoic acid in a $500 \mathrm{~mL}$ beaker. The mixture was stirred at room temperature for $30 \mathrm{~min}$ until complete reaction and a clear solution was obtained. The solution was filtered to isolate any unreacted moieties of benzoic acid then concentrated using a rotatory evaporator. The concentrate was poured into $300 \mathrm{~mL}$ acetone to precipitate sodium benzoate as white clear crystals. The precipitate was filtered then transferred immediately to a glass dish and left to dry overnight then put in an oven for complete dryness at $105{ }^{\circ} \mathrm{C}$ for $3 \mathrm{~h}$. The dried precipitate was grinded to a fine powder using a Teflon tool then put in a closed bottle and kept in a desiccator. 


\subsection{Purity Assessment of the Synthesized Benzoate for the Preparation of the RM batch}

The purity of the synthesized sodium benzoate used for the preparation of the RM batch was measured by the quantitative Nuclear Magnetic Resonance (qNMR) at the National Metrology Institute of Turkey (UME) and was found $99.699 \pm 0.231$ indicating a highly pure material. The maleic acid reference was used as the internal standard and its purity was determined within the traceability chain by chloramphenicol primary calibrant with UME-CRM-1301 by qNMR.

\subsection{Preparation of the RM Batch}

A plastic container $(15 \mathrm{~L})$ was cleaned with acidified ultrapure water (5\% nitric acid) then dried and weighed empty using a calibrated balance. Then a mass of the dried synthesized sodium benzoate calculated by equation 1 was weighed by a another calibrated balance $(11.19 \mathrm{~g})$ and dissolved in $500 \mathrm{~mL}$ ultrapure water in a clean beaker then poured into the plastic container. The beaker was rinsed three times with ultrapure water and poured into the container and then ultrapure water was added until the mass of solution reaches $11000 \mathrm{~g}(11 \mathrm{~kg})$. Concentration of the prepared RM batch was calculated using equation 1 and was found $1014.473 \mathrm{mg} / \mathrm{kg}$.

$$
C(m g / k g)=\frac{m(m g) x p(\text { mass fraction })}{m_{S o \text { In }}(k g)}
$$

The prepared RM batch was homogenized by mechanical shaking for one night, then bottled into 100 HDPE bottles each is $100 \mathrm{~mL}$.

\subsection{Equipment}

\subsubsection{HPLC-UV Method}

The HPLC-UV system used was of the model Ulti Mate 3000 equipped with an auto-sampler, quaternary pump and a UV detector of the same model. The column used for separation was of the type hypersll gold $(50 \mathrm{~mm} \times 2.1 \mathrm{~mm} \times 1.9 \mu \mathrm{m})$ and the software was Chromeleon 6.0. The mobile phase was assembled from $90 \%$ acetate buffer and $10 \%$ acetonitrile (v:v). Acetate buffer was prepared by dissolving $0.3 \mathrm{~g}$ ammonium acetate in $900 \mathrm{~mL}$ ultrapure water and its $\mathrm{pH}$ was adjusted to 4.2 by adding about $0.5 \mathrm{~mL}$ of glacial acetic acid, then it was filtered and sonicated for 10 minutes before use. The flow rate was 0.25 $\mathrm{mL} / \mathrm{min}$ and the injection volume was $10 \mu \mathrm{L}$ while the column temperature was kept at $21^{\circ} \mathrm{C}$.

\subsubsection{UV-VIS-NIR Spectrophotometer}

The UV-VIS-NIR spectrophotometer used was Hitachi UH4150, Japan with an automatic wavelength correction and a pair of $1 \mathrm{~cm}$ matched quartz cells. The spectral band width was $1 \mathrm{~nm}$ and the wave length accuracy was $0.3 \mathrm{~nm}$. Sodium benzoate samples were measured in aqueous solution at 225 nm.

\subsection{3. $L C-M S / M S$}

The LC-MS/MS used for sodium benzoate characterization was manufactured by Thermo Scientific, model UltiMate 3000 equipped with a quaternary pump, an autosampler of the same model and a mass detector of model TSQ Quantum. Chremelone and Xcalibur software packages were used to run the instrument. The chromatographic separation was performed, using a hypersll gold HPLC column (50 $\mathrm{mm} \times 2.1 \mathrm{~mm} \times 1.9 \mu \mathrm{m}$ ) and the mobile phase was assembled from acetate buffer and methanol 65:35\%, $(\mathrm{v} / \mathrm{v})$. Acetate buffer was prepared as described above then $50 \mathrm{~mL}$ of it were added to $150 \mathrm{~mL}$ ultrapure 
water. The injection volume was $10 \mu \mathrm{L}$, flow rate was $0.35 \mathrm{~mL} / \mathrm{min}$ and the column temperature was kept at $21^{\circ} \mathrm{C}$. The ion source (ESI) parameters were: spray voltage, $3500 \mathrm{~V}$, vaporizer temperature, $200{ }^{\circ} \mathrm{C}$, the sheath gas pressure, $40 \mathrm{psi}$, the aux gas pressure, $10 \mathrm{psi}$ and the capillary temperature was $270^{\circ} \mathrm{C}$. The precursor-to-product ion pair used for the SRM was $\mathrm{m} / \mathrm{z} 121 \rightarrow 77 \mathrm{~m} / \mathrm{z}$ at collision energy (CE) $14 \mathrm{~V}$ in the negative ionization mode and the acusation time was 3 min.

\subsection{Calibration of the Measuring Equipment}

A stock solution, of the sodium benzoate CRM was prepared as about $500 \mathrm{mg} / \mathrm{kg}$ by dissolving $50.6 \mathrm{mg}$ in ultrapure water in a $100 \mathrm{~mL}$ flask. In addition, a stock solution of internal standard (IS) was also prepared as about $500 \mathrm{mg} / \mathrm{kg}$ by dissolving $51.22 \mathrm{mg}$ of sodium salicylate in ultrapure water in a 100 mL flask. Calibration solutions: 5, 10, 20,30, 40 and $50 \mathrm{mg} / \mathrm{kg}$ were prepared by dilution from the CRM stock solution using equation 2 .

where,

$$
c_{1} x m_{1}=c_{2} x m_{2}
$$

$c_{1} \quad$ : concentration of the stock solution

$m_{1}$ : mass taken from the stock solution

$c_{2} \quad$ : diluted concentration

$m_{2}$ : mass of the diluted solution

The internal standard was added to each calibration level as about $25 \mathrm{mg} / \mathrm{kg}$ in case of calibration of HPLC-UV instrument only. Meanwhile, calibration of LC-MS/MS was external since very good linearity and repeatability of the method were obtained. The UV-VIS-NIR spectrophotometer was also calibrated using the same levels, $5,10,20,30,40$ and $50 \mathrm{mg} / \mathrm{kg}$.

\subsection{Homogeneity Assessment}

ISO guide 35 recommends three units for the homogeneity study of hundred units, and we have selected two units more. This number agrees with number calculated by taking the cubic root of 100 which is 4.64 that can be rounded to 5. The five bottles have been randomly selected so that one bottle represents the top of the container, one represents the middle, one represents the bottom, one represents the between top and middle and the fifth bottle represents the between middle and bottom of the container. Each bottle was divided into three sub-samples and the measurements were carried out by the HPLC-UV in one run under repeatability conditions.

\subsection{Stability Assessment}

The short term stability of sodium benzoate RM solution was studied by the isochronous approach in which three bottles were stored in a refrigerator at $4^{\circ} \mathrm{C}$, one bottle for 3 weeks, one for 2 weeks and the third bottle was stored for 1 week. Other three bottles were stored in an oven at $40^{\circ} \mathrm{C}$ also for 3, 2 and 1 weeks respectively. The seventh bottle was stored at a well-controlled room temperature, $\left(21 \pm 2{ }^{\circ} \mathrm{C}\right)$ for three weeks. After storage time was over, samples were left to reach room temperature before analysis. Each bottle was divided into three portions and each portion was diluted to $30 \mathrm{mg} / \mathrm{kg}$ and measured once. One sample from those stored at $4{ }^{\circ} \mathrm{C}$ and another one from those stored at $40{ }^{\circ} \mathrm{C}$ were stored at $-5^{\circ} \mathrm{C}$ as reference temperature for $24 \mathrm{~h}$ then measured at room temperature. Meanwhile, the long term stability was measured by the classical approach under storage at room temperature $\left(21 \pm 2{ }^{\circ} \mathrm{C}\right)$ for 1 , 3,6 , and 12 months [10]. For this long term stability study, other four bottles were randomly selected, so that one bottle is used at each time point. Each bottle was divided into two portions and each portion was measured five times so that the total number of measurents is 10 . In both studies, the measurements were carried out under repeatability conditions by the UV-VIS-NIR spectrophotometer calibrated in the range $5-50 \mathrm{mg} / \mathrm{kg}$. 


\section{Results and Discussion}

\subsection{Traceability of the Measurement Results}

Traceability of the measurement results to the SI units was ensured by calibration of the three measuring equipment, HPLC-UV, LC-MS/MS and the UV-VIS-NIR spectrophotometer using sodium benzoate CRM $(99.997 \pm 0.232)$ and by the gravimetric preparation of the stock solutions and the diluted calibration solutions using a calibrated analytical balance $(0.01 \mathrm{mg})$.

\subsection{Evaluation of the Material Homogeneity}

Before characterization, a decision on homogeneity of the prepared reference material was required. Five bottles were randomly selected and each of them was divided into three sub-samples. The sub-samples were diluted and each was measured in duplicate so that the total number of measurements per bottle was six. Measurements were carried out by HPLC-UV in one run under repeatability conditions using the simple random design. The results obtained are shown in Table 1. These results were statistically analyzed by ANOVA-single factor as shown in Table 2. From this table, it can be seen that F is smaller than $\mathrm{F}_{\text {critical }}$ and the $p$ value is larger than 0.05 . This indicates that no significant differences were found between the RM bottles which, indicates that the prepared reference material is homogeneous.

Table 1. The homogeneity assessment results $(\mathrm{mg} / \mathrm{kg})$ of the candidate RM

\begin{tabular}{ccccc}
\hline Bottle 1 & Bottle 2 & Bottle 3 & Bottle 4 & Bottle 5 \\
\hline 53.11 & 53.31 & 52.71 & 45.91 & 55.17 \\
53.07 & 53.02 & 52.44 & 42.36 & 55.17 \\
52.86 & 52.55 & 52.87 & 52.48 & 52.86 \\
52.39 & 55.70 & 52.46 & 52.58 & 53.45 \\
53.73 & 53.63 & 52.40 & 53.01 & 53.55 \\
53.38 & 45.76 & 52.18 & 53.49 & 52.70 \\
\hline
\end{tabular}

Table 2. ANOVA-single factor of the homogeneity results

\begin{tabular}{|c|c|c|c|c|c|c|}
\hline ANOVA & & & & & & \\
\hline Source of Variation & $S S$ & $d f$ & $M S$ & $\boldsymbol{F}$ & P-value & F crit \\
\hline Between Groups & 50.20695 & 4 & 12.55174 & 1.801243 & 0.160177 & 2.75871 \\
\hline Within Groups & 174.2093 & 25 & 6.968374 & & & \\
\hline Total & 224.4163 & 29 & & & & \\
\hline
\end{tabular}

Since the mean square $M S_{\text {between }}$ is larger than $M S_{\text {within }}$ the uncertainty of the material homogeneity $\left(\sigma_{h}\right)$ was calculated as 1.02 using equation 3 [17-20].

$$
\sigma_{h}=\sqrt{\frac{M S_{\text {between }}-M S_{\text {within }}}{n}}
$$

where,

$M S_{\text {between }}$ : mean square for between groups

$M S_{\text {within }} \quad$ : mean square for within groups

$n \quad:$ number of measurements per bottle 


\subsection{Evaluation of the Material Stability}

The stability of a reference material is an essential requirement to ensure that the possible adverse effects of temperature, humidity and light are avoided [11,21-24]. The results obtained of the short term stability, $u_{s t s}$ of samples stored at room temeratureare $(21 \pm 2), 4^{\circ} \mathrm{C}$ and at $40^{\circ} \mathrm{C}$ for one, two and three weeks are shown in Table 4. From this table, it is clear that the smallest concentration is $30.02 \mathrm{mg} / \mathrm{kg}$ and the largest one is $30.25 \mathrm{mg} / \mathrm{kg}$, which means that the measured samples slightly differe from each other and their concentrations seem to be almost stable.This can also be seen from Figure 1 in which the results were also multiplied by the dilution factor and plotted against the storage time in weeks. The maximum time for shipment was decided 3 weeks and uncertainty of the short term stability was calculated on that basis according to equation 4 and was found $0.003 \mathrm{mg} / \mathrm{kg}$, which was neglected in the certified uncertainty calculation.

$$
u_{s t s}=\frac{R S D}{\sqrt{\sum\left(t_{i}-\bar{t}\right)^{2}}} t
$$

where,

$$
\begin{array}{ll}
R S D & \text { : relative standard deviation } \\
t_{i} & : \text { time point for each replicate } \\
t^{-} & : \text {average of all storage time points } \\
t & : \text { time suggested for shipment (3 weeks) }
\end{array}
$$

\begin{tabular}{|c|c|c|}
\hline \multicolumn{2}{|c|}{ Storage time (week) } & \multirow{2}{*}{$\frac{\text { Measurement results }(\mathrm{mg} / \mathrm{kg})}{30.09}$} \\
\hline \multirow{3}{*}{ At $21^{\circ} \mathrm{C}$} & \multirow{3}{*}{3} & \\
\hline & & 30.08 \\
\hline & & 30.08 \\
\hline \multirow{9}{*}{ At $4{ }^{\circ} \mathrm{C}$} & \multirow{3}{*}{1} & 30.18 \\
\hline & & 30.19 \\
\hline & & 30.18 \\
\hline & \multirow{3}{*}{2} & 30.24 \\
\hline & & 30.22 \\
\hline & & 30.22 \\
\hline & \multirow{3}{*}{3} & 30.25 \\
\hline & & 30.22 \\
\hline & & 30.23 \\
\hline \multirow{9}{*}{ At $40^{\circ} \mathbf{C}$} & \multirow{3}{*}{1} & 30.02 \\
\hline & & 30.04 \\
\hline & & 30.04 \\
\hline & \multirow{3}{*}{2} & 30.20 \\
\hline & & 30.22 \\
\hline & & 30.22 \\
\hline & \multirow{3}{*}{3} & 30.16 \\
\hline & & 30.15 \\
\hline & & 30.16 \\
\hline & Average & 30.16 \\
\hline & $\mathrm{SD}$ & 0.07 \\
\hline & RSD & $0.24 \%$ \\
\hline
\end{tabular}

Table 3. The short term stability results of the RM samples. 

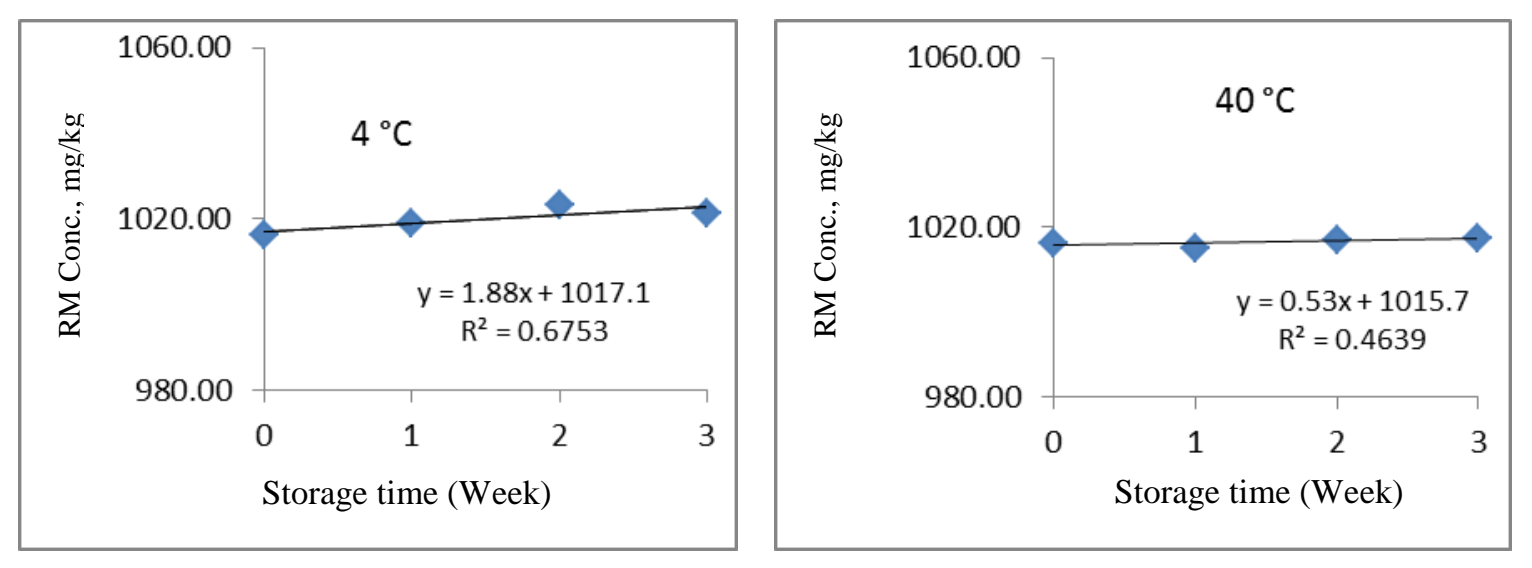

Figure 1. Short term stability plots at $4{ }^{\circ} \mathrm{C}$ and $40{ }^{\circ} \mathrm{C}$

From these results, it can be concluded that the material can be transported to customers at ambient temperature up to $40{ }^{\circ} \mathrm{C}$ in a maximum of three weeks.

The long term stability results are shown in Table 4 . They were multiplied by the dilution factor and averages of the measured values at the 4 time points were calculated as, 1018.18, 1016.78, 1017.47 and $1018.51 \mathrm{mg} / \mathrm{kg}$ respectively.

Table 4. The long term stability concentration results of the RM samples at 1, 3, 6 and $12(\mathrm{M})$

\begin{tabular}{l|cccc}
\hline Time points & $\mathbf{1 ~ M}$ & $\mathbf{3 ~ M}$ & $\mathbf{6 ~ M}$ & $\mathbf{1 2} \mathbf{M}$ \\
\hline & 25.17 & 25.97 & 25.89 & 25.83 \\
Concentration, & 25.19 & 25.99 & 26.07 & 25.83 \\
$\mathrm{mg} / \mathrm{kg}$ & 25.19 & 25.97 & 25.89 & 25.83 \\
& 25.19 & 25.97 & 25.87 & 25.85 \\
& 25.17 & 25.97 & 25.87 & 25.85 \\
& 25.19 & 25.99 & 25.87 & 25.85 \\
& 25.19 & 26.01 & 25.87 & 25.85 \\
& 25.21 & 25.99 & 25.87 & 25.83 \\
& 25.19 & 26.01 & 25.87 & 25.83 \\
Average & 25.21 & 25.97 & 25.89 & 25.83 \\
Dil. Factor & 25.19 & 25.99 & 25.9 & 25.83 \\
RM Conc & 40.42 & 39.13 & 39.29 & 39.42 \\
\hline
\end{tabular}

By visual inspection of these averages, it can clearly be noticed that the concentration of the RM is almost stable along the period of study since the difference between the gravimetrically prepared concentration $(1014.473 \mathrm{mg} / \mathrm{kg})$ and the largest measured one $(1018.51 \mathrm{mg} / \mathrm{kg})$ is about $4 \mathrm{ppm}$, which is a very small variation. In addition, the RM concentrations at the different time points in relation to the gravimetric concentration $(1014.473 \mathrm{mg} / \mathrm{kg})$ were looked at within the uncertainty limits of the certified value $( \pm 10.43 \mathrm{mg} / \mathrm{kg})$ as shown in Figure 2 . 


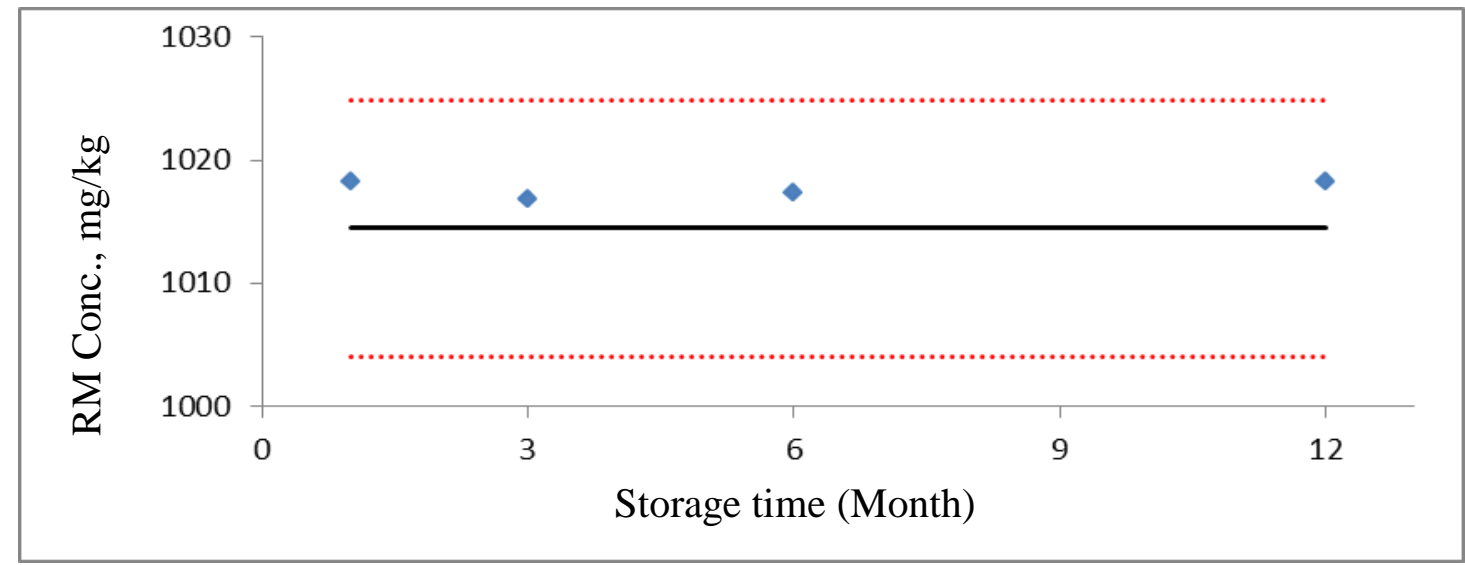

Figure 2. The long-term stability results within the certified uncertainty limits

From this figure, it can be clearly seen that the material concentration did not deviate from the uncertainty limits along the period of study indicating a clear stability of the prepared reference material. To calculate uncertainty of the long-term stability, $u_{l t s}$ the time points $(\mathrm{M})$ were plotted against the RM concentration to produce the regression line shown in Figure 3.

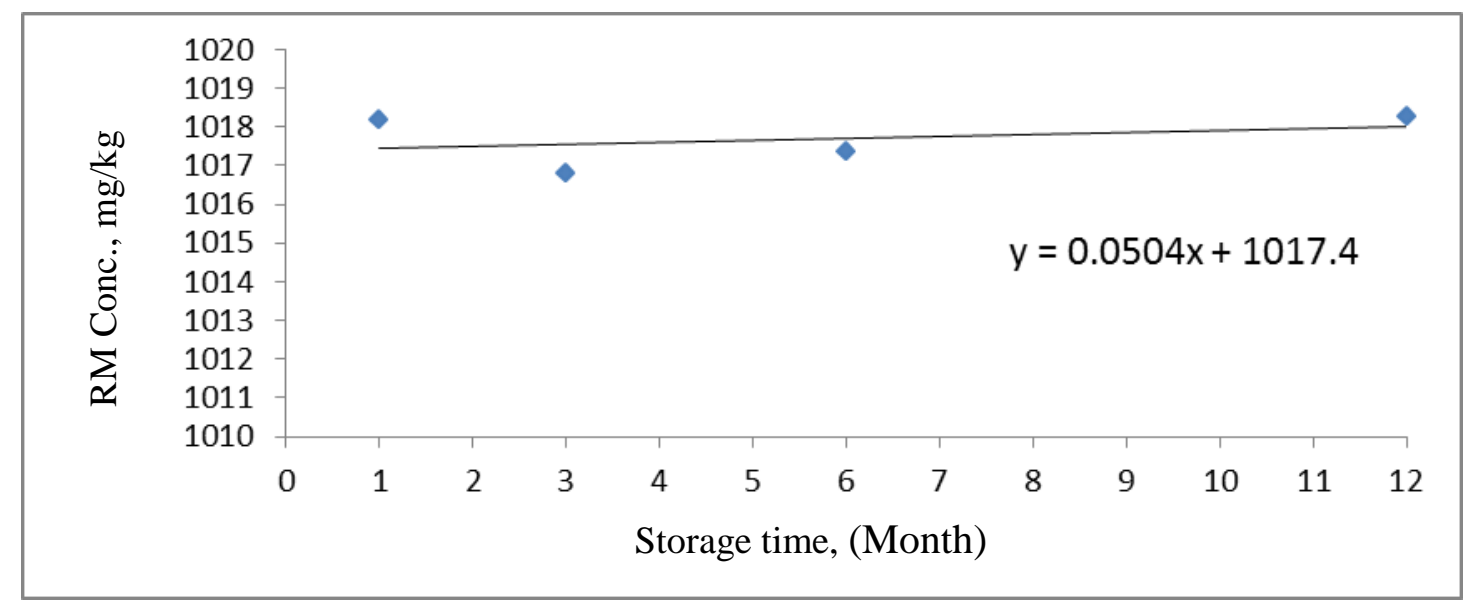

Figure 3. The long-term stability time points (M) vs. RM concentration (mg/kg)

Uncertainty was calculated as $\pm 0.15 \mathrm{mg} / \mathrm{kg}$ using equation 5 in which the slope of the line (0.0504) was multiplied by the shelf time $\left(t_{c e r t}\right)$ given to the material which is 3 years.

$$
u_{\text {lts }}=\text { Slope } x \quad\left(t_{\text {cert }}\right)
$$

\subsection{Characterization of the Sodium Benzoate RM}

Characterization of the prepared sodium benzoate solution reference material was carried out in accordance with the approach of characterization of a non-operationally defined measurand using two or more methods of demonstrable accuracy in one laboratory [10]. The HPLC-UV (M1), LC-MS/MS (M2) and UV-VIS-NIR spectrophotometer (M3) methods were used for characterization along three days. To ensure traceability of the measurement results to the SI units, each of the three instruments was calibrated daily using the sodium benzoate CRM diluted to 5, 10, 20,30, 40 and $50 \mathrm{mg} / \mathrm{kg}$ calibration levels. Each 
calibration level was injected 5 times and the calibration curves were obtained by plotting the CRM concentration $(x)$ against the instrument response $(y)$. Typical calibration curves of HPLC-UV, UV-VISNIR spectrophotometer and LC-MS/MS are shown in Figure 4.
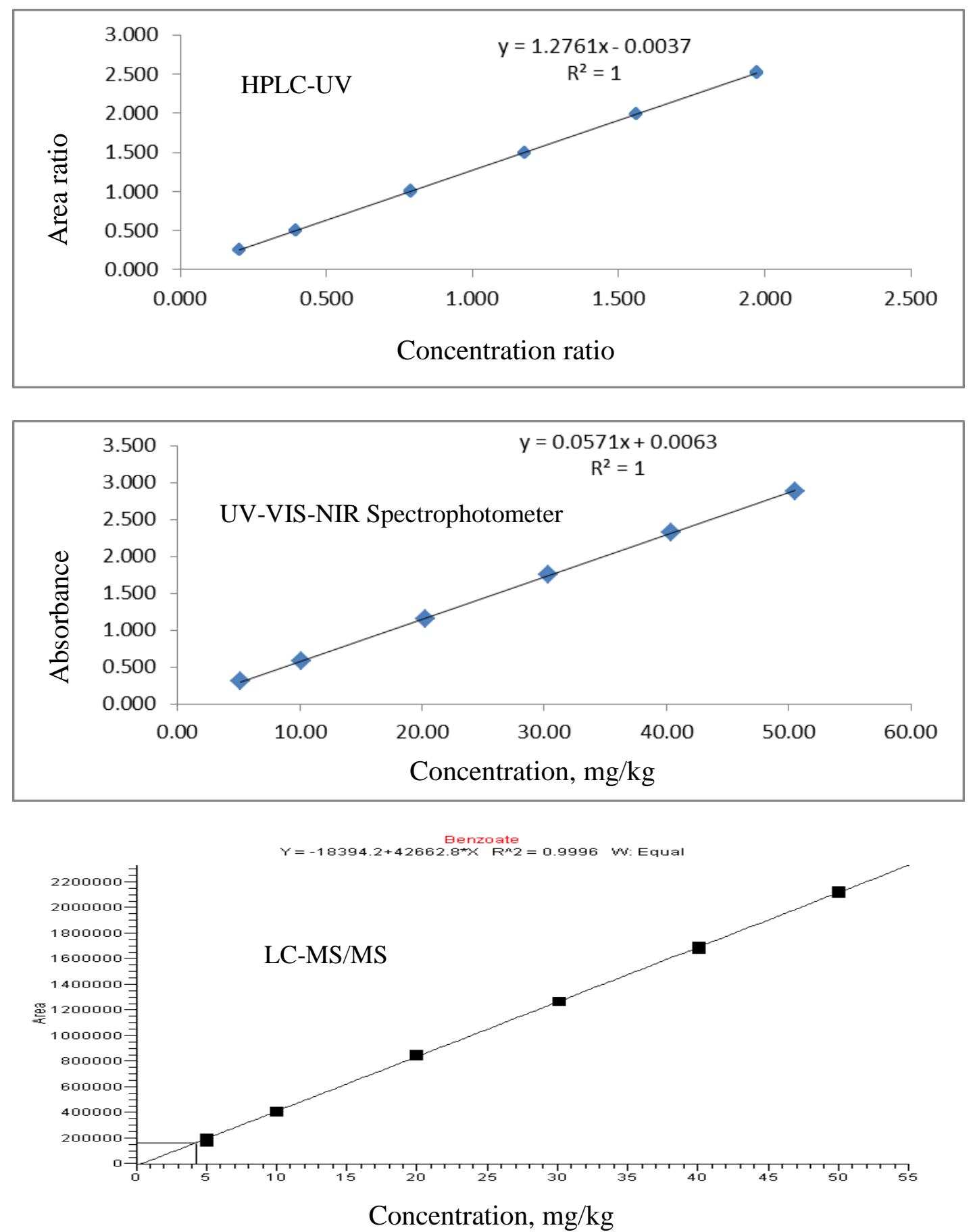

Figure 4. Typical calibration curves of the three measuring equipment

Linearity of each of these curves was assessed by calculating the residuals and plotting them around an axis of zero as shown in Figure 5. From these plots, it can be seen that the residuals are randomly distributed around zero indicating a very good linearity of the curves [25]. 

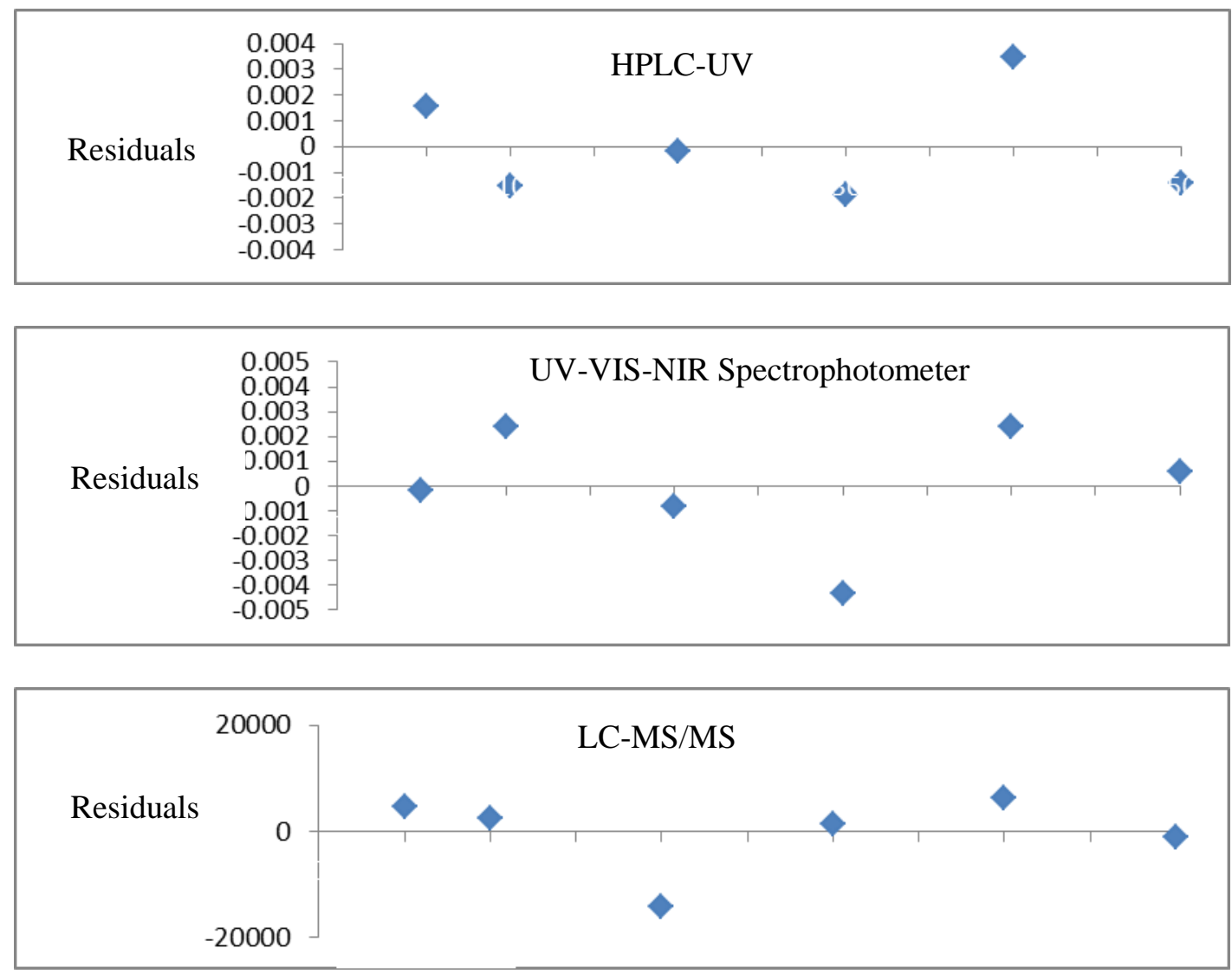

Figure 5. The residuals of the calibration curves of the three measuring equipment

The characterization study was carried out using two selected bottles. Each bottle was divided into three portions. One sample from each portion was prepared as $25 \mathrm{mg} / \mathrm{kg}$ by dilution every day and two samples were measured by each equipment 5 times then the averages were calculated. The average dilution factors of the samples in the three days were found $40.57,40.33$ and 40.57 for the three methods respectively. The diluted samples were measured every day and the concentration $(x)$ was calculated by excel using the linear equation as: $x=y-b / a$ where $y$ is the area ratio in case of HPLC, the area in case of LC-MS/MS and the absorbance in case of UV-VIS-NIR spectrophotometer. The slope of the curve was, $a$ while the intercept was, $b$. A typical chromatogram of HPLC-UV is shown in Figure 6 (a) in which the scale of the retention time is: $0.0,0.5,1.0,1.5,2.0,2.5,3.0,3.5,4.0,4.5$ and $5.0 \mathrm{~min}$. In this chromatogram, the peak of sodium benzoate appeared at $4.1 \mathrm{~min}$ and the peak of sodium salicylate (IS) appeared at 1.95 min. Meanwhile a typical chromatogram of LC-MS/MS is shown in Figure 6 (b) in which the peak of sodium benzoate appeared at $1.45 \mathrm{~min}$.

The results obtained by the three methods in the three days (D1-D3) are shown in Table 5. From this table, it can be clearly observed that the three methods gave almost similar average results (25.02, 25.13 and $25.21 \mathrm{mg} / \mathrm{kg}$ ) and a very good repeatability of measurements indicated from the RSD\% values $(0.28,1.23$ and 0.32$)$ was obtained where the precision is clearly smaller than $5 \%$.

Multiplying the obtained RM average concentration of each method by the corresponding dilution factor, we get 1015.06 for HPLC-UV, 1016.72 for LC-MS/MS and $1019.52 \mathrm{mg} / \mathrm{kg}$ for the UV-VIS spectrophotometer. The three values agree very well within the certified uncertainty $( \pm 10.43 \mathrm{mg} / \mathrm{kg})$ and they are very close to the RM gravimetric concentration, $(1014.473 \mathrm{mg} / \mathrm{kg})$ which imparts a strong traceability link of the measurement results to the SI units. 

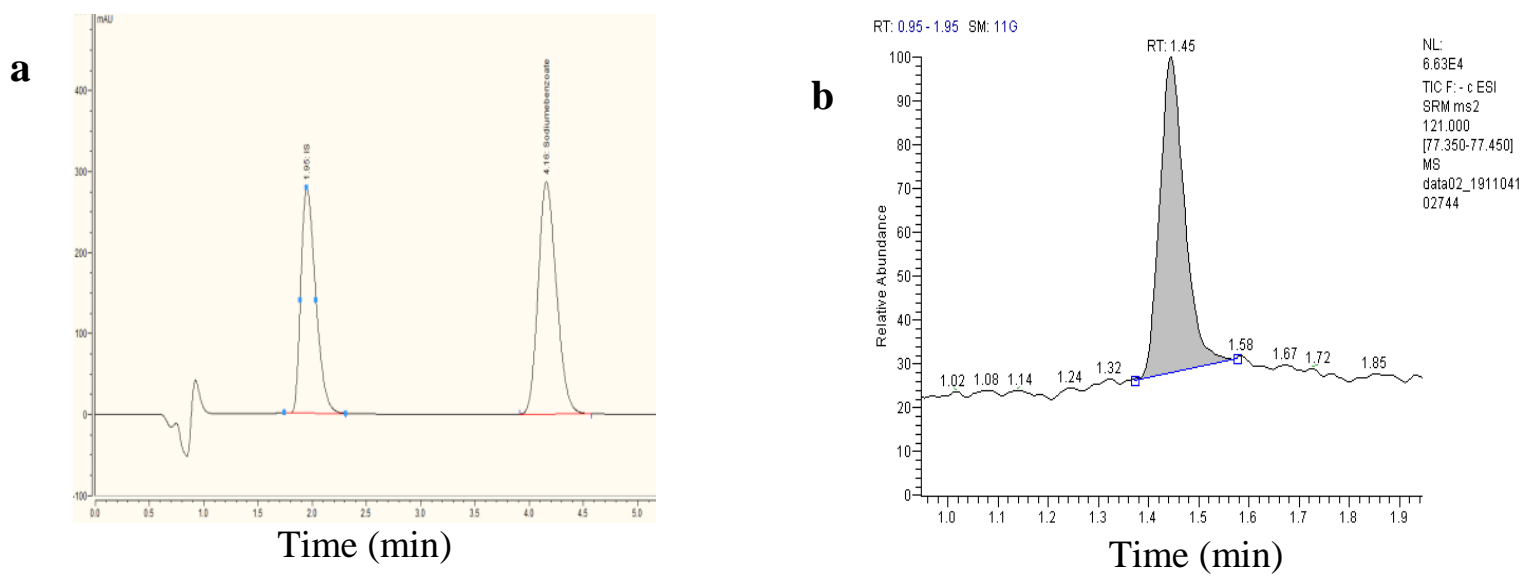

Figure 6. Typical chromatograms produced by HPLC-UV (a) and LC-MS/MS (b)

Table 5. The characterization results $(\mathrm{mg} / \mathrm{kg})$ by the three methods in D1-D3

\begin{tabular}{lccc}
\hline \multicolumn{1}{c}{ Days } & HPLC-UV (M1) & LC-MS/MS (M2) & UV-VIS Spectrophotometer (M3) \\
& 25.01 & 24.77 & 25.20 \\
D 1 & 24.96 & 24.77 & 25.20 \\
& 25.07 & 25.30 & 25.21 \\
& 24.94 & 24.95 & 25.21 \\
& 25.04 & 24.71 & 25.21 \\
\hline \multirow{2}{*}{ D 2 } & 24.97 & 25.50 & 25.12 \\
& 25.02 & 25.33 & 25.12 \\
& 25.13 & 25.75 & 25.12 \\
& 24.91 & 25.35 & 25.12 \\
& 25.14 & 25.44 & 25.12 \\
\hline D 3 & 25.03 & 25.22 & 25.31 \\
& 24.99 & 24.90 & 25.31 \\
& 25.08 & 25.07 & 25.31 \\
Average & 24.99 & 24.97 & 25.31 \\
SD & 25.09 & 24.92 & 25.31 \\
RSD\% & 25.02 & 25.13 & 25.21 \\
$\boldsymbol{u}_{\boldsymbol{c}}$ (mg/kg) & 0.07 & 0.31 & 0.08 \\
\hline
\end{tabular}

\subsection{Assigning Value to the RM}

The certified value of the sodium benzoate solution reference material was derived as a weighted mean by combing the data obtained from the three characterization methods [25-27]. As indicated by ISO guide 35, approaches described for combing the results of the characterization of a reference material by two methods or more including their uncertainties into a single value and a combined standard uncertainty, include weighing results by their uncertainties. ISO guide 35 also points Paule and Mandel approach as one them [28]. We have adopted this approach which is well described in reference No 10 for combing our data and uncertainties, because it gives due consideration to the between method differences 
and makes allowances for dispersion of the method results. The steps followed to reach the certified value and its uncertainty using this approach were: (a) estimation of the combined standard uncertainty of each method mean according to ISO GUM and EURACHEM/CITAC guide, (b) estimation of the between method variance and the weight of each method mean, (c) estimation of the weighted mean (certified value) (d) calculation of the bias allowance as the largest absolute difference between the method means and the certified value, (e) estimation of the effective degrees of freedom and then the certified uncertainty.

Since ISO guide 35 states that: the RM producer should check whether there is evidence of deviation from the assumed distribution using, for example, statistical checks for departure from particular distributions, including tests for normality, we began our calculations by checking the distribution. The normality test (Kolmogorov-Smirnov test) was carried out (statistical package Minitab 16), to check the distribution before combing the data. In this test, concentration of the RM was plotted against a theoretical normal distribution where data should form an approximate straight line, as shown in Figure 8 which represents data of the HPLC-UV method as an example. From this figure, it is noticed that the points form a nearly linear pattern and no departures from this straight line were observed, which indicates that the normal distribution of the data is a good model [16].

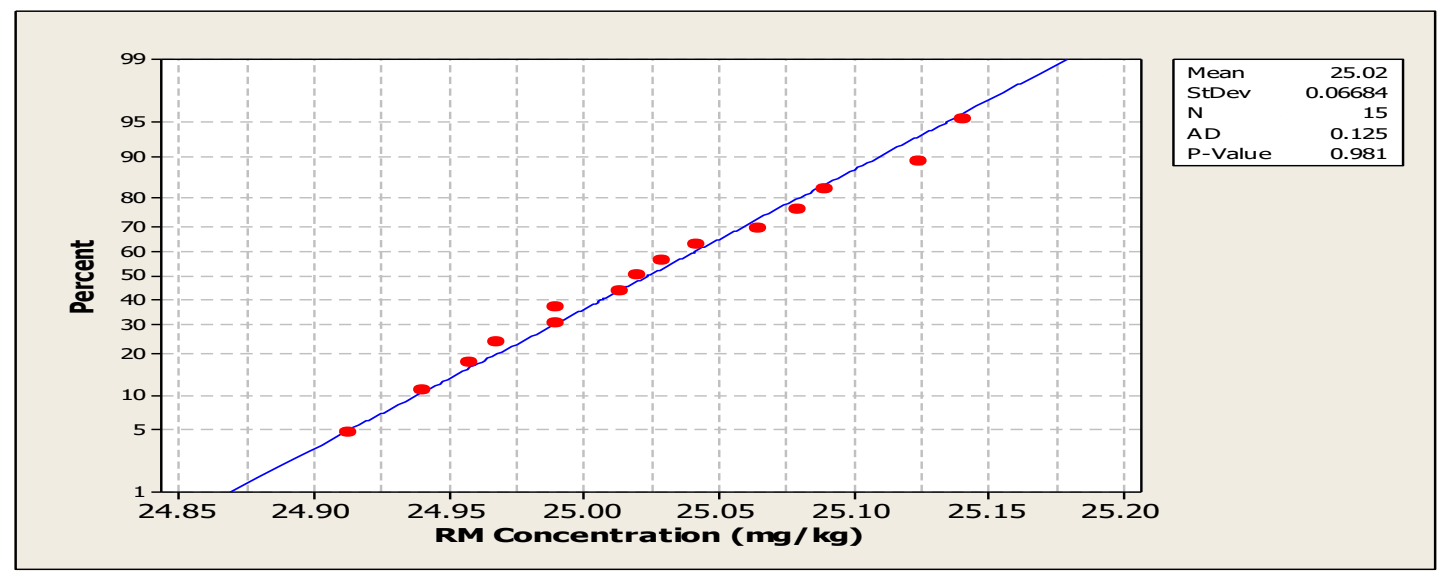

Figure 7. Normality test of HPLC-UV data

\subsubsection{Estimation of the Combined Standard Uncertainty of the RM Characterization, $S_{i}$}

Uncertainty of the characterization of sodium benzoate RM by the three methods was calculated as per ISO GUM and Eurachem/CITAC guide [31,29]. Sources of uncertainty were: mass of sample, stock solution of the CRM, stock solution of the internal standard (IS) in case of HPLC-UV method only, calibration and repeatability of measurements. All masses were weighed by a calibrated analytical balance of $0.01 \mathrm{mg}$ sensitivity. The calibration standard uncertainty was calculated as: $3.070 \times 10^{-7} \times R$, at $95 \%$, where $R$ is the mass as indicated in the calibration certificate of the balance, and his uncertainty was multiplied by 2 to compensate for tare as in equation 6 . Uncertainty of the mass of sample was then calculated using equation 7.

$$
\begin{gathered}
u(m)=\sqrt{2 x\left(u_{c a l}\right)^{2}} \\
u\left(m_{\text {sample }}\right)=\sqrt{\left(u_{m R M}\right)^{2}+\left(u_{m I S}\right)^{2}+\left(u_{m \mathrm{H}_{2} \mathrm{O}}\right)^{2}}
\end{gathered}
$$


Uncertainty of the CRM stock solution was calculated using equation 8 in which contribution from the CRM purity was included.

$$
u_{c}(C R M \text { Stock })=\sqrt{\left(\frac{u_{\text {purity } C R M}}{\text { Purity }}\right)^{2}+\left(\frac{u_{m C R M}}{m C R M}\right)^{2}+\left(\frac{u_{m H_{2} O}}{m H_{2} O}\right)^{2}}
$$

For the HPLC-UV calibration, sodium salicylate was used as an internal standard and uncertainty of its stock solution was calculated using equation 9.

$$
u_{c}(I S \text { Stock })=\sqrt{\left(\frac{u_{\text {purity IS }}}{\text { Purity }}\right)^{2}+\left(\frac{u_{m I S}}{m I S}\right)^{2}+\left(\frac{u_{m H_{2} O}}{m H_{2} O}\right)^{2}}
$$

The uncertainty of the repeatability of measurements was calculated from equation 10 , where $S D$ is the standard deviation and, $n$ is the number of measurements.

$$
u(\operatorname{Re} p t)=\frac{S D}{\sqrt{n}}
$$

With regard to uncertainty of the calibration curve, $u\left(x_{\text {pred }}\right)$, it was calculated according to equations 11 and 12 since the weighed linear regression is our model for regression analysis [29], where, $b_{1}$ is the slope of the calibration curve, $\left(x_{\text {pred }}-\bar{x}\right)^{2}$ is the difference between $x_{\text {pred }}$ and the mean, $\bar{x}$ of the calibration points $x_{1}, x_{2}, \ldots \ldots . x_{n}$ and $\operatorname{Var}\left(y_{o b s}\right)$ is the variance of the average, $\overline{\mathrm{x}}$ of the measured concentration.

$$
\begin{gathered}
\operatorname{Var}\left(x_{\text {pred }}\right)=\frac{\operatorname{Var}\left(y_{\text {obs }}\right)}{b_{1}^{2}}+\frac{S^{2}}{b_{1}^{2}} \cdot\left(\frac{1}{\sum w_{i}}+\frac{\left(x_{\text {pred }}-\bar{x}\right)^{2}}{\left(\sum\left(w_{i} x_{i}^{2}\right)-\left(\frac{\left(\sum w_{i} x_{i}\right)^{2}}{\sum w_{i}}\right)\right.}\right) \\
u\left(x_{\text {pred }}\right)=\sqrt{\operatorname{Var}\left(x_{\text {pred }}\right)}
\end{gathered}
$$

In addition, $S^{2}$ is the residual standard error and was calculated according to equation 13 [29], in which $y_{i}$ - $y_{f i t}$ is the residual error for the $i^{\text {th }}$ point, $n$ is the number of calibration points and, $w_{i}$ is the weighting factor [30] of each individual calibration concentration. It was calculated using equation 14, in which, $n$ is the number of calibration points and $s_{i}$ is the standard deviation.

$$
\begin{gathered}
S^{2}=\frac{\sum w_{i}\left(y_{i}-y_{f i}\right)^{2}}{(n-2)} \\
w_{i}=\frac{n s_{i}^{-2}}{\sum s_{i}^{-2}}
\end{gathered}
$$

The weighting factors $w_{i}$ were used to calculate the slope, $b_{1}$ (in equation 11) for the weighted linear regression according to equation 15 [30] where $x_{i}$ is the calibration concentration and $y_{i}$ is the response. 


$$
b_{1}=\frac{n \sum_{i=1}^{n} w_{i} x_{i} y_{i}-\sum_{i=1}^{n} w_{i} x_{i} \sum_{i=1}^{n} w_{i} y_{i}}{n \sum_{i=1}^{n} w_{i} x_{i}^{2}-\left(\sum_{i=1}^{n} w_{i} x_{i}^{2}\right)^{2}}
$$

The combined standard uncertainty, $u_{c}$, of each method mean was calculated using equation 16 in which $C_{0}$ is the measured concentration of the RM sample and the uncertainty contributions were taken as relative amounts. The $u_{c}$ results of the three methods are listed in Table 5 .

$$
u_{c}=C_{0} \sqrt{\left(\frac{{ }_{\text {m sample }}^{\text {Sample mass }}}{2}\right)^{2}+\left(\frac{{ }^{u} \text { CRM Stock }}{C \text { stock }}\right)^{2}+\left(\frac{{ }^{u} \text { IS Stock }}{C \text { IS }}\right)^{2}+\left(\frac{{ }^{u} \text { Cal curve }}{C_{0}}\right)^{2}+\left(\frac{{ }^{u} \operatorname{Re} p t}{C_{0}}\right)^{2}}
$$

\subsubsection{Calculation of the Method Weight $\left(W_{i}\right)$}

In order to calculate the method weight $\left(W_{i}\right)$, the between method variance, $\sigma_{b}$ was calculated by equation 17.

where,

$$
\sigma_{b}=\sqrt{\frac{M S_{\text {between }}-M S_{\text {within }}}{n}}
$$

$$
\begin{array}{ll}
M S_{\text {between }} & : \text { mean square for between groups } \\
M S_{\text {within }} & : \text { mean square for within groups } \\
n & : \text { number of runs (3) }
\end{array}
$$

The characterization results of the three methods in three days (D1-D3) were analyzed by ANOVA-single way, which showed that the mean squares $M S_{\text {between }}$ and $M S_{\text {within }}$ were 0.132305 and 0.052375 respectively. The $\sigma_{b}$ was found 0.163 and together with the combined standard uncertainty, $S_{i}$ was used to calculate the weight of each method $W_{i}$ by equation 18 .

where,

$$
W_{i}=\left[\frac{1}{S_{i}^{2}+\sigma_{b}^{2}}\right]
$$

$\mathrm{W}_{\mathrm{i}}$ : weight of the method mean

$S_{i} \quad$ : combined standard uncertainty

$\sigma_{\mathrm{b}}$ : between method variance

The weighing factor of each method, $w_{i}$ was then calculated by equation 19 in which $n$ is the number of methods. All the calculated values were reported in Table 6.

$$
w_{i}=\frac{W_{i}}{\sum_{1}^{n} W_{i}}
$$


Table 6. Combined uncertainty $S_{i}$, the method weight $W_{i}$ and weighing factor $w_{i}$

\begin{tabular}{l|ccc}
\hline Parameter & \multicolumn{3}{c}{ Method } \\
Combined standard uncertainty, $u_{c}\left(S_{i}\right) x$ Dil. Factor, $\mathrm{mg} / \mathrm{kg}$ & 4.95 & 15.82 & 4.44 \\
Between method variance, $\sigma_{b}, \mathrm{mg} / \mathrm{kg}$ & & 0.163 & \\
Method weight, $W_{i}$ & 0.041 & 0.004 & 0.051 \\
Weighing factor, $w_{i}$ & 0.427 & 0.042 & 0.031 \\
\hline
\end{tabular}

\subsubsection{The Certified Value and the Weighted Uncertainty}

The weighted mean of each method has been calculated by equation 20 [11], in which the mean of each method, $\bar{x}_{i}$ was multiplied by the corresponding weighing factor of the method, $w_{i}$. Then the certified value $\overline{\bar{Y}}$ was calculated by summation of the weighted means of the methods.

$$
\overline{\bar{Y}}=\sum_{1}^{n} w_{i} \overline{x_{i}}
$$

In addition, the characterization weighted uncertainty, $u_{\text {char }}$, has been calculated by taking the square root of the summation of squares of the weighted uncertainties of the methods according to equation 21 [11].

$$
u_{\text {char }}=\sqrt{\sum_{1}^{n} w_{i}^{2} S_{i}^{2}}
$$

The bias allowance, $B$ is the largest absolute difference between the methods means $\bar{x}_{i}$ and the certified value, $\overline{\bar{Y}}$ and has been found $3.39 \mathrm{mg} / \mathrm{kg}$ according to equation 22 [11].

$$
B=\max \left|\overline{x_{i}}-\overline{\bar{Y}}\right|
$$

\section{5.4. Calculation of the coverage factor, $k$}

The effective degrees of freedom $v_{\text {eff }}$ of the total variance was calculated using Satterthwaite equation 23 in which $n_{i}-1$ is the degrees of freedom (4) of the method mean, and $d f_{h}$ equals 14 , which is the number of samples measured in duplicate in the homogeneity study minus $1[11]$.

$$
v_{e f f}=\frac{\left(\sum_{1}^{M} w_{i}^{2} S_{i}^{2}+\hat{\sigma}_{h}^{2}\right)^{2}}{\left(\sum_{1}^{M} \frac{\left(w_{i}^{2} S_{i}^{2}\right)}{n_{i}-1}+\frac{\hat{\sigma}_{h}^{4}}{d f_{h}}\right)}
$$

The obtained $v_{\text {eff }}$ value, 22.48, was used to identify the corresponding coverage factor, $k$ at confidence level of $95 \%$ from the $\mathrm{t}$-table which was found 2.09. Values of all the calculated parameters were reported in Table 8.

\section{5.5. Uncertainty of the Certified Value}

Uncertainty of the certified value, $U_{C R M}$ has been estimated according to equation 24 in which $k$ is the coverage factor, $u_{c h a r}^{2}$ is the weighted uncertainty of the characterization methods, $u_{\text {homo }}^{2}$ is the 
uncertainty of the RM homogeneity, $u_{l t s}^{2}$ is the uncertainty of the long-term stability and $B$ is the bias allowance $[11,10]$. The estimated UCRM value was found $10.47 \mathrm{mg} / \mathrm{kg}$ and was reported in Table 7 .

$$
U_{C R M}=k \sqrt{u_{\text {char }}^{2}+u_{\mathrm{homo}}^{2}+u_{l t s}^{2}}+B
$$

Table 7. The weighted mean (certified value) and the certified uncertainty

\begin{tabular}{|c|c|c|c|}
\hline \multirow[b]{2}{*}{ Parameter } & \multicolumn{3}{|c|}{ Method } \\
\hline & M1 & M2 & M3 \\
\hline Method weighted mean, $w_{i} \bar{X}_{i}$ & 10.68 & 1.05 & 13.39 \\
\hline Weighted mean (certified value) $\overline{\bar{Y}}, \mathrm{mg} / \mathrm{kg}$ & & 1016.13 & \\
\hline Method weighted uncertainty, $w_{i}^{2} S_{i}^{2}$ & 4.46 & 5.55 & 0.44 \\
\hline Characterization uncertainty, $\mathrm{u}_{\text {char }}\left(\sqrt{ }\right.$ Dil Factor $\left.x w_{i}^{2} S_{i}^{2}\right)$ & & 3.23 & \\
\hline Uncertainty of homogeneity, uhomo $_{\text {ho }} \mathrm{mg} / \mathrm{kg}$ & & 1.02 & \\
\hline Uncertainty of long-term stability, $u_{l t s}, \mathrm{mg} / \mathrm{kg}$ & & 0.15 & \\
\hline Bias allowance, $B, \mathrm{mg} / \mathrm{kg}$ & & 3.39 & \\
\hline Effective degrees of freedom, $v_{\text {eff }}$ & & 22.48 & \\
\hline Coverage factor, $k$ & & 2.09 & \\
\hline Certified uncertainty, $U_{C R M}, \mathrm{mg} / \mathrm{kg}$ & & 10.47 & \\
\hline
\end{tabular}

\section{Conclusion}

Sodium benzoate solution reference material was prepared and its homogeneity and stability were assessed. The candidate RM was characterized by three accurate and precise independent analytical methods and the certified value $(1016.13 \pm 10.47 \mathrm{mg} / \mathrm{kg})$ was derived as weighted mean and uncertainty by combing data from the three methods with traceability to the SI units. The sodium benzoate solution CRM has been produced in full compliance with ISO 17034 and ISO guides 35 and it can be used for calibration of measuring equipment and for quality control as well as for proficiency testing purposes in food and drug testing laboratories.

\section{ORCID}

Adel B. Shehata: 0000-0002-6818-4825

Abdulrahman. R. Alaskar: 0000-0002-9846-5265

Mohammed. A. Alrasheed: 0000-0003-1392-9516

Abdullah. S. Alosaimi: 0000-0003-2464-0689

Fahd. A. Alkharraa: 0000-0002-9051-8131

Abdulrahman. M. Alzahrani: $\underline{0000-0003-1077-4678}$

\section{References}

[1] P. De Bièvre, R. Dybkaer, A. Fajgelj and D. B. Hibbert (2011). Metrological traceability of measurement results in chemistry: Concepts and implementation (IUPAC Technical Report), Pure Appl. Chem. 83(10), 1873-1935.

[2] E. Hendrik, H. Andrea and U. Franz (2006). Reference materials as crucial tools for quality assurance and control in food analysis, Pure Appl. Chem. 78 (1), 135-43.

[3] A. B. Terry and K. B. Blair (2013). Rapid, direct quantitation of the preservatives benzoic and sorbic acid (and salts) plus caffeine in foods and aqueous beverages using supercritical chromatography, Chromatographia 76, 393-99.

[4] The international vocabulary of metrology-basic and general concepts and associated terms, VIM (2008). 3rd Edition. 
[5] I. F. Tahoun and A. B. Shehata (2016). Development of four parabens reference materials certified for purity mass fraction by mass balance approach, MAPAN J. Metrol. Soc. Ind. 31, 45-52.

[6] I. F. Tahoun, R. N. Yamani and A. B. Shehata (2019). Preparation of matrix reference material for quality assuranceand control of pesticides analysis in olive oil, Accred. Qual. Assur. 24, 297-304

[7] A. C. Goren, G. Bilsel, A. Simsek, M. Bilsel, F. Akcadag, K. Topal and H. Ozgen (2015). HPLC and LCMS/MS methods for determination of sodium benzoate and potassium sorbate in food and beverages: Performances of local accredited laboratories via proficiency tests in Turkey, Food Chem. 175, 273-79.

[8] M. Dzieciol, A. Wodnicka and E. Huzar (2010). Analysis of preservative content in food, Proceed. ECOpole, 25-28.

[9] ISO 17034: General requirements for the competence of reference material producers (2016). $1^{\text {st }}$ Edition.

[10] ISO Guide 35: Reference materials-guidance for characterization and assessment of homogeneity and stability (2017). $4^{\text {th }}$ Edition.

[11] S. B. Schiller and K. R. Eberhardt (1991). Combining data from independent chemical analysis methods, Specrtrochim. Acta 46B, 12, 1607-1613.

[12] I. F. Tahoun and A. B. Shehata (2010). Preparation and certification of a fish oil natural matrix reference material for organochlorine pesticides, Accred. Qual. Assur. 15, 563-68.

[13] A. B. Shehata, M. S. Rizk, A. M. Farag and I. F. Tahoun (2014). Certification of three reference materials for a-and $\mathrm{y}$-tocopherol in edible oils, Mapan 29, 183-94.

[14] A. B. Shehata, M. S. Rizk, A. M. Farag and I. F. Tahoun (2015). Development of two reference materials for all trans-retinol, retinyl palmitate, $\alpha$ - and $\gamma$-tocopherols in milk powder and infant formula, J. Food. Drug Anal. 23, 82-92.

[15] A. B. Shehata, M. Gabr and M. A. Gab-Allah (2017). Development of crude oil reference material certified for the concentrations of sulfur, iron, nickel, vanadium and magnesium, MAPAN J. Metrol. Soc. Ind. 32(2), 101-112.

[16] A. B. Shehata, M. S. Rizk and E. A. Rend (2016). Certification of caffeine reference material purity by ultraviolet/visible spectrophotometry and high-performance liquid chromatography with diode-array detection as two independent analytical methods, J. Food Drug Anal. 24, 703-715.

[17] T. P. Linsinger, J. Pauwels, A. M. Van der Veen, H. Schimmel and A Lamberty (2001). Homogeneity and stability of reference materials, Accred. Qual. Assur. 6, 20-25.

[18] J. Pauwels, A. Lamberty and H. Schimmel (1998). Homogeneity testing of reference materials, Accred. Qual. Assur. 3, 51-55.

[19] M. Ulberth-Buchgraber, M. Potalivo, H. K. Emteborg and A. Held (2011). Toward the development of certified reference materials for effective biodiesel testing. Part 1: processing, homogeneity, and stability, Energy Fuel. 25, 4622-4629.

[20] I. F. Tahoun and A. B, Shehata (2016). Preparation of honey reference material for water content by Karl Fisher and refractometric methods, MAPAN J. Metrol. Soc. Ind. 31, 25-29

[21] C. Jimenez, R. Ventura, J. Segura and R. De la Torre (2004). Protocols for stability and homogeneity studies of drugs for its application to doping control, Anal. Chim. Acta 515, 323-331.

[22] A. Van der Veen and J. Pauwels (2000). Uncertainty calculations in the certification of reference materials. 1. Principles of analysis of variance, Accred. Qual. Assur. 5, 464-469.

[23] M. Koch, W. Bremser, R. K€oppen, R. Kruger, T. Rasenko, D. Siegel and I. Nehls (2011). Certification of reference materials for ochratoxin A analysis in coffee and wine, Accred. Qual. Assur. 16, 429-437.

[24] A. M. Van der Veen, T. P. Linsinger, A. Lamberty and J. Pauwels (2001). Uncertainty calculations in the certification of reference materials, Accred. Qual. Assur. 6, 257-263.

[25] K. Danzer and L. A. Currie (1998). Guidelines for calibration in analytical chemistry. Part I. Fundamentals and single component calibration (IUPAC Recommendations, Pure Appl. Chem. 70, 993-1014.

[26] S. B. Schiller (1996). Statistical aspects of the certification of chemical batch SRMs, National Institute of Standards and Technology (NIST). Spec. Publ. 260-125.

[27] W. May, R. Parris, C. Beck, J. Fassett, R. Greenberg, F. Guenther, G. Kramer, S. Wise, T. Gills , J. Colbert, R. Gettings and B. MacDonald (2000). National Institute of Standards and Technology (NIST) . Spec. Publ. 260-136.

[28] R.C. Paule and J. Mandel (1982). Consensus values and weighting factors, J. Res. Nat. Inst. Stand. Technol. 87, 377-385

[29] Eurachem/CITAC guide (2013): quantifying uncertainty in analytical measurement, $3^{\text {rd }}$ Edition. 
[30] D. Harvey, Modern Analytical Chemistry (2000). The McGraw-Hill Companies Inc, USA, 1st ed. P 124 125.

[31] BIPM, IEC, IFCC, ISO, IUPAC, IUPAP, OIML (1993). Guide to the expression of uncertainty in measurement. 1st ed. Geneva,Switzerland: ISO.

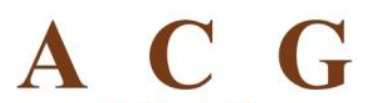

publications

(C) 2020 ACG Publications 